\title{
A region on chicken chromosome 2 affects both egg white thinning and egg weight
}

\author{
Mervi HONKATUKIA $^{\text {a* }}$, Maria TUISKULA-HAAVISTO ${ }^{\mathrm{a}}$, \\ Dirk-Jan DE KONING ${ }^{\mathrm{b}}$, Anneli VIRTA ${ }^{\mathrm{a}}$, Asko MÄKI-TANILA ${ }^{\mathrm{a}}$, \\ Johanna VILKKI ${ }^{\mathrm{a}}$ \\ ${ }^{a}$ Animal Production Research, MTT Agrifood Research Finland, 31600 Jokioinen, Finland \\ ${ }^{\mathrm{b}}$ Roslin Institute, Roslin, Midlothian EH25 9PS, UK
}

(Received 28 February 2005; accepted 2 May 2005)

\begin{abstract}
We describe the results from genetic dissection of a QTL region on chicken chromosome 2, shown to affect egg weight and quality in an earlier genome scan of an $F_{2}$ intercross between two divergent egg layer lines. As the $90 \%$ confidence intervals for the detected QTL covered tens of centiMorgans, new analyses were needed. The datasets were reanalysed with denser marker intervals to characterise the QTL region. Analysis of a candidate gene from the original QTL region, vimentin, did not support its role in controlling egg white thinning. Even after reanalysis with additional seven markers in the QTL area, the $90 \%$ confidence intervals remained large or even increased, suggesting the presence of multiple linked QTL for the traits. A grid search fitting two QTL on chromosome 2 for each trait suggested that there are two distinct QTL areas affecting egg white thinning in both production periods and egg weight in the late production period. The results indicate possible pleiotropic effects of some of the QTL on egg quality and egg weight. However, it was not possible to make a distinction between close linkage versus pleiotropic effects.
\end{abstract}

chicken / chromosome 2 / egg quality / egg weight / QTL mapping

\section{INTRODUCTION}

During the last ten years, many QTL have been detected in poultry affecting production traits including growth rate, carcass traits and feed efficiency $[4,6,10,13,15,27,32,37,38]$, as well as disease resistance $[36,42-44,46]$. Most of these studies were done on experimental chicken populations from crosses involving broilers or exotic lines. Far less attention

*Corresponding author: mervi.honkatukia@mtt.fi

The nucleotide sequence data reported in this paper have been submitted to GenBank Submission nucleotide database (Accession Numbers AY694786-AY694792). 
has been paid to egg quality traits such as egg white thinning or shell quality, although these are also economically important [40]. In a recent study Sasaki et al. [24] reported QTL affecting egg quality traits (egg shell strength, shell colour, shape of egg), however egg white quality was not included.

One of the major contributors to the interior quality of eggs is the egg white. Egg white thinning is a sign of quality loss that leads to staleness. Fresh and firm egg white restricts microbial growth because egg white proteins have antimicrobial properties [21], while thin and "runny" egg white exposes the egg to microbial infections due to altered structure and biochemical composition. Thin egg white also has an unfavourable impact on the hatchability of chicken embryos [2].

Fresh egg albumen consists of four major parts: two thick and two thin whites in addition to chalazae. The major portion (approximately half) of the albumen consists of the outer thick white. The thick white is a firm jelly-like gel that contains microscopic fibrils. The chalazae and the thick egg white are required to keep the yolk in the center of the egg. It is important that any contact between the yolk and shell membranes is avoided in order to prevent microbial growth in the yolk. A large proportion of thick egg white is also desirable in the food industry for foaming and heat coagulation for baking. When the egg is stored, the albumen becomes more fluid and less gelatinous [17]. However, this varies greatly according to breed and health conditions of the hens. Albumen also thins during incubation. Probably the decrease in viscosity is necessary for the rapid diffusion of albumen protein to the embryo [2].

Egg white thinning is regulated by very complex processes [3] and can be regarded as a quantitative trait. The heritability $\left(h^{2}\right)$ estimates for albumen quality range from very low to high [41], an average estimate being $0.38[19,20,28]$. The genetic correlation between egg white thinning and egg production (egg number) is slightly negative [19]. The genetic correlation between egg size and albumen quality has been negative in several studies cited by Washburn [41]. As a result, selection for increased egg production may result in decreased egg white quality. In some situations (e.g. when the responsible genes are closely linked), it could therefore be advantageous to be able to directly select individuals by genotype or linked markers.

We have previously detected QTL regions affecting egg white thinning on chromosomes 2, 4 and 8 [35]. The QTL region on chromosome 2 harbouring genome-wide significant QTL effects on both egg white thinning and egg weight was chosen for further study. The $90 \%$ confidence interval area coincides with the location of several putative egg quality candidate genes, including vimentin among others [25]. Vimentin belongs to a family of intermediate 
filaments, which are important in maintaining the mechanical integrity of the cell $[23,45]$. Moreover, the intermediate filaments make stiff gel-like structures through polymerisation [30].

In the present study, we describe the genetic dissection of the chromosome two QTL region. Multiple marker regression, including grid search for multiple QTL, was used together with denser marker intervals.

\section{MATERIALS AND METHODS}

\subsection{Mapping population and phenotypic observations}

The mapping population was based on a reciprocal intercross of two parental lines, the White Leghorn (WL) and Rhode Island Red (RIR). The parent generation consisted of four animals per line. The $\mathrm{F}_{2}$ population of 305 individuals was achieved by mating eight $F_{1}$ males with $32 F_{1}$ females [35]. The two parental chicken lines diverged mainly for egg quality. The RIR line eggs were slightly lighter $(61.5 \mathrm{~g})$ than those of the WL $(63.9 \mathrm{~g})$, and the HU scoring of egg white height in the RIR line was lower $(53.0 \mathrm{HU})$ than in the WL line (91.0 HU).

The production period was divided into two parts. The first part includes a period from 18 to 40 weeks of age, during which time egg production reaches the highest potential and optimal egg weight. During the second period from 41 to 60 weeks of age the egg white quality slowly decreases, whereas egg weight increases $[8,31]$.

Albumen height was scored in Haugh units (HU). HU is a function of the height of the thick albumen and the weight of the egg corrected to a constant $56.7 \mathrm{~g}$ egg [11]. The HU scoring was done three times. First, for eggs collected during 36 to 39 weeks (HU40), secondly for eggs collected during 57 to 59 weeks of age (HU60). For each hen, one egg was collected per week; the HU values used in the QTL analysis were the averages within each observation period. For the third time, the effect of storage was studied from eggs laid at the age of 60 weeks and thereafter stored for 28 days (the length of the sales period on the market) at $+8{ }^{\circ} \mathrm{C}$ (stored $\mathrm{HU}$ ) to detect any possible genetic effect on the rate of albumen quality decline. In the $\mathrm{F}_{2}$ mapping population, the mean of stored HU was 57.6 with a standard deviation of 10.0.

Egg weight was recorded as the mean of weekly measurements (1 egg/week) during two periods: early production, EWa (between 18 and 40 weeks of age) and late production, EWb (between 41 and 60 weeks of age). The phenotypic 
data were pre-adjusted for hatch effect. No other systematic environmental effects were observed or adjusted.

\subsection{Marker genotyping}

The first genome scan incorporated genotypes of 13 markers spanning $351 \mathrm{cM}$ of chromosome 2 [35]. The new analysis was done with six additional microsatellite markers (MCW0220, LEI0117, MCW0243, MCW0206E, LEI0089 and MCW0264) and an SNP marker (VIMint4) within the QTL region. The additional microsatellites were chosen from Compton (C), East Lansing (EL) and Wageningen (WAU) genetic maps (https://acedb.asg.wur.nl). In addition, several markers were tested but excluded on the grounds of being uninformative (LEI0247, MCW0142, ADL309, MCW0131, ADL0197, ADL0185, LEI0086 and MCW0184). Microsatellite marker genotyping and analysis were done using standard protocols [35]. MegaBACE Genetic Profiler (Amersham Biosciences) software was used to determine the genotypes of the microsatellite markers.

Sequence information was available from chicken vimentin [45], and it was analysed for variation within the mapping population. VIMint4 is a single nucleotide polymorphism within the vimentin gene, detected by sequencing four individuals of the mapping population. Sequencing primers were designed based on information of the DNA sequence of the chicken vimentin gene, GenBank ${ }^{\mathrm{TM}} / \mathrm{EMBL}$ accession number J02759 (gi: 212864-212866). A few animals representing extreme HU values were selected to be sequenced. Several polymorphic sites were identified in vimentin, mainly in the introns (Tab. I). One of the polymorphisms, VIMint4 (an A to G change within the intron between exons 4 and 5) was used as a marker in linkage analysis. The VIMint4 was scored using minisequencing Snupe Genotyping (Amersham Biosciences). An amplified PCR product of the region (forward primer: 5'-GTG TCC TCT TCG AGT GAG TG; and reverse: 5'-GAA AAT CCA AAA CAT GTA) was used as a template in a thermally cycled minisequencing reaction with dye-labelled terminators and sequence specific primer ending one base before the polymorphic base $\left(5^{\prime}\right.$ - CCT GGG TCT AGA AGT AGT $\mathrm{CC})$. Excess deoxynucleotides and primers were removed with specific enzymatic treatment of the reaction product before minisequencing (ExoSap-IT TM Amersham Biosciences). Unincorporated dye-labelled terminators were subsequently removed by filtration (AutoSeq ${ }^{\mathrm{TM}} 96$ plates, Amersham Biosciences). Reaction products were detected on a capillary DNA electrophoresis instrument (MegaBACE, Amersham Biosciences). Analysis was based on allele 
Table I. Location of polymorphisms and detected nucleotide variants in the vimentin gene.

\begin{tabular}{ccc}
\hline $\begin{array}{c}\text { Position \# nt of } \\
\text { genebank sequence }\end{array}$ & \#exon / intron & Polymorphisms \\
\hline 255 of 212869 & 5'flanking & A / G \\
259 of 212869 & 5'flanking & A / T \\
406 of 212869 & 5'flanking & A / G \\
613 of 212869 & 5'flanking & C / T \\
643 of 212869 & 5'flanking & C / T \\
762 of 212869 & 5'flanking & A / C \\
257 of 323864 & 5'flanking & A / G \\
520 of 212864 & 5'flanking & A / G \\
1207 of 212864 & exon 1 & A / G \\
21 of 212865 & exon 3 & C / G \\
145 of 212865 & intron 3 & A / G \\
107 of 212866 & intron 4 & A / G \\
328 of 212866 & intron 5 & T / G \\
381 of 212866 & intron 5 & T / G \\
389 of 212866 & intron 5 & C / T \\
431 of 212866 & intron 5 & C / T \\
818 of 212866 & intron 5 & C / T \\
892 of 212866 & intron 5 & A / C \\
1173 of 212866 & intron 6 & A / C \\
1796 of 212866 & intron 8 & C / T \\
1875 of 212866 & intron 8 & A / G \\
2139 of 212866 & intron 8 & A / G \\
2169 of 212866 & intron 8 & C / T \\
\hline
\end{tabular}

${ }^{1}$ VIMint 4 , the SNP included in the linkage analysis.

signal intensity and relative allele mobility using MegaBACE SNP Profiler, version 1.0 (Molecular Dynamics 2001).

\subsection{Linkage analysis}

A linkage map of the 20 markers on chicken chromosome 2 was constructed using CRIMAP, version 2.4 [9]. All pairwise combinations of markers were first checked using the "two-point" option. The order of markers within the 
linkage group was determined with option BUILD. The superiority of the current order of adjacent markers was compared with possible optional orders using FLIPS. Option CHROMPIC was used to detect genotyping errors (double or triple recombinants).

\subsection{Regression analysis}

QTL Express, a web-based application (http://qtl.cap.ed.ac.uk) [26] of linear regression, was used for QTL analyses, as well as a similar custom-made program to perform additional permutations of the data, and bootstrapping to obtain the threshold values for statistical test and the $90 \%$ confidence intervals. Analyses were done by fitting either one or two QTL simultaneously for each trait (HU40, HU60, stored HU or EWa, EWb) on chromosome 2.

An empirical permutation test (10000 iterations) was applied to determine significance thresholds for $5 \%$ and $1 \%$ chromosome wide significance levels. Confidence intervals for QTL positions were determined by bootstrapping [39]. The $90 \%$ cut-off points of sorted best test statistics from 10000 bootstrap replicates were calculated using the custom-made program and were used to define the boundaries of the confidence interval [5].

For the two QTL model, an F-test was used to determine whether the best QTL pair explained significantly more of the variation than the best single QTL from the pair.

\section{RESULTS}

\subsection{QTL mapping}

The average information content was $>0.6$ along the chromosome. This was a clear improvement compared with the previous study [35]. The new analyses with 20 markers showed a significant QTL affecting HU40, with the best position at $137 \mathrm{cM}$ between markers MCW0206E (114 cM) and ADL0217 $(152 \mathrm{cM})$, thus falling in the previously established QTL area (Tab. II). The effect of the RIR allele was $-3.73 \mathrm{HU}( \pm 0.80)$, while the dominance effect was $-1.74 \mathrm{HU}( \pm 1.51)$. The detected QTL explained $6.7 \%$ of the phenotypic variance. The $90 \%$ confidence interval for the QTL location was broadened from the previous $58 \mathrm{cM}$ to $64 \mathrm{cM}$ despite the denser marker map. Auxiliary analyses, fitting two QTL simultaneously, indicated the existence of two distinct QTL areas affecting HU40 at $141 \mathrm{cM}$ (hereafter named HU QTL-1) and 54 cM (HU QTL-2) (Tab. III). 
Table II. QTL for egg white quality (HU40, HU60) and late egg weight (EWb) by one QTL model in chromosome 2. The effect was calculated as the effect of the allele from the parental RIR line.

\begin{tabular}{cccccc}
\hline Trait & F-ratio $^{1}$ & Position (cM) & $\begin{array}{c}\text { Additive } \\
\text { effect } \\
(\mathrm{s} . \mathrm{e})\end{array}$ & $\begin{array}{c}\text { Dominance } \\
\text { effect } \\
(\mathrm{s.e})\end{array}$ & $\begin{array}{c}\text { 90\% C.I of } \\
\text { QTL position }\end{array}$ \\
\hline HU40 & $\begin{array}{c}11.34 \\
(\mathrm{p}<0.01)\end{array}$ & 137 & $-3.73( \pm 0.80)$ & $-1.74( \pm 1.51)$ & $97-161$ \\
HU60 & $\begin{array}{c}7.06 \\
(\mathrm{p}<0.01)\end{array}$ & 139 & $-5.50( \pm 1.48)$ & $\mathrm{ns}$ & $128-150$ \\
EWa & $\begin{array}{c}4.05 \\
(\mathrm{p}>0.05)\end{array}$ & 137 & $\mathrm{~ns}$ & $\mathrm{~ns}$ & $\mathrm{~ns}$ \\
$\mathrm{EWb}$ & $\begin{array}{c}6.54 \\
(\mathrm{p}<0.05)\end{array}$ & 12 & $-0.45( \pm 0.60)$ & $-3.80( \pm 1.09)$ & $0-48$ \\
\hline
\end{tabular}

${ }^{1}$ Chromosome-wide significance shown in parentheses.

${ }^{2}$ Empirical confidence intervals based on $\mathrm{F}$ ratios (bootstrapped 10000 times, custom-made program).

Table III. QTL for egg white quality (HU40, HU60) and late egg weight (EWb) from the two QTL model. The effect was calculated as the effect of the allele from the parental RIR line.

\begin{tabular}{|c|c|c|c|c|c|c|c|}
\hline Trait & $\begin{array}{c}\text { F ratio } \\
2 v s .0 \text { QTL }\end{array}$ & $\begin{array}{c}\text { F-ratio } \\
2 \text { vs. } 1 \text { QTL }\end{array}$ & $\begin{array}{l}\text { Positions } \\
\text { of QTL }\end{array}$ & $\begin{array}{c}\text { Add. effect } \\
\text { of QTL } 1\end{array}$ & $\begin{array}{c}\text { Dom. effect } \\
\text { of QTL } 1\end{array}$ & $\begin{array}{c}\text { Add. effect } \\
\text { of QTL } 2\end{array}$ & $\begin{array}{c}\text { Dom. effect } \\
\text { of QTL } 2\end{array}$ \\
\hline HU40 & $\begin{array}{c}7.89 \\
(p<0.001)^{1}\end{array}$ & $\begin{array}{c}4.13 \\
(p<0.025)^{1}\end{array}$ & $\begin{array}{c}54 \text { (QTL2) and } \\
141 \text { (QTL1) }\end{array}$ & $\begin{array}{c}-3.38 \\
( \pm 0.82)\end{array}$ & $\mathrm{ns}$ & $\begin{array}{c}-1.49 \\
( \pm 0.70)\end{array}$ & $\begin{array}{c}2.26 \\
( \pm 1.06)\end{array}$ \\
\hline HU60 & $\begin{array}{c}6.58 \\
(p<0.005)^{1}\end{array}$ & $\begin{array}{c}5.82 \\
(p<0.005)^{1}\end{array}$ & $\begin{array}{c}32 \text { (QTL2) and } \\
140 \text { (QTL1) }\end{array}$ & $\begin{array}{c}-5.90 \\
( \pm 1.51)\end{array}$ & $\begin{array}{c}-3.11 \\
( \pm 2.80)\end{array}$ & ns & $\begin{array}{c}6.70 \\
( \pm 2.03)\end{array}$ \\
\hline EWb & $\begin{array}{c}6.37 \\
(\mathrm{p}<0.005)^{1}\end{array}$ & $\begin{array}{c}5.98 \\
(p<0.005)^{1}\end{array}$ & $\begin{array}{c}12 \text { (QTL2) and } \\
\text { (QTL1) } 83\end{array}$ & $\begin{array}{c}-1.70 \\
( \pm 0.54)\end{array}$ & $\begin{array}{c}1.08 \\
( \pm 0.79)\end{array}$ & ns & $\begin{array}{c}-4.09 \\
( \pm 1.10)\end{array}$ \\
\hline
\end{tabular}

${ }^{1}$ nominal p-level.

In the previous genome scan no strong evidence for a QTL affecting the egg white thinning in the later laying period (HU60) was found. However, reanalysis with the denser map revealed a significant QTL effect on HU60, the most probable location being $2 \mathrm{cM}$ distant from the one for HU40 (Tab. II). 
The additive effect on HU60 was higher $(-5.50 \pm 1.48)$ than it was on HU40 and also the $90 \%$ confidence interval was narrower $(22 \mathrm{cM})$. The analyses of fitting two QTL revealed a second QTL area at $32 \mathrm{cM}$. There the additive effect was not significant, but the dominance effect was markedly higher than the dominance affecting HU40 at QTL-2 $(6.70 \pm 2.03$ versus $2.26 \pm 1.06)$ (Tab. III).

At both QTL locations, the RIR allele had a decreasing additive effect on HU scores in both production periods, which is congruent with egg white quality features of the RIR line. At the HU QTL-2, the dominance effect was fairly high and contrary to the additive effect.

In the first genome scan, no QTL was identified to affect Haugh values in stored eggs. Neither did reanalysis reveal any significant association between marker polymorphism and egg white thinning variation after storage.

A genome-wide significant QTL affecting egg weight in the late production period was previously found on chromosome 2 . The most likely position (a $65 \mathrm{cM}$-wide 90\% confidence interval) for the QTL located within a large gap between the flanking markers MCW0247 and ADL0217. The marker information content at that position was low $(<0.3)$. In the refined study, the improvement of map resolution placed the QTL at $12 \mathrm{cM}$; with a significant dominance effect $(-3.80 \pm 1.09)$ (Tab. II). Fitting two QTLs indicated that there was more than one QTL affecting the egg weight in the late production period. The specified locations of the two QTLs appeared to be on both sides of the former marker gap area. The effect of EWb QTL 2 (position of $12 \mathrm{cM}$ ) was dominant $(-4.09 \pm 1.10)$ and EWb QTL 1 (position of $83 \mathrm{cM}$ ) weakly additive $(-1.70 \pm 0.54)$. At both positions the RIR allele had a negative effect on egg weight. No significant effect was found for egg weight in the high production period (EWa). However, the test statistic reached its highest value close to $\mathrm{HU}$ QTL-1 area (Tab. II).

\subsection{Sequencing of vimentin}

Almost the entire chicken vimentin gene was sequenced from two hens with high and two hens with low Haugh values to identify possible variation associated with egg white quality. In the coding sequence, two polymorphisms were identified between good and poor quality hens. Several polymorphisms were detected in the 5'-flanking area and the introns (Tab. I). One polymorphism (VIMint4) was included in the linkage analysis as an SNP marker, which was studied in the entire $\mathrm{F}_{2}$ mapping population. The linkage analysis 


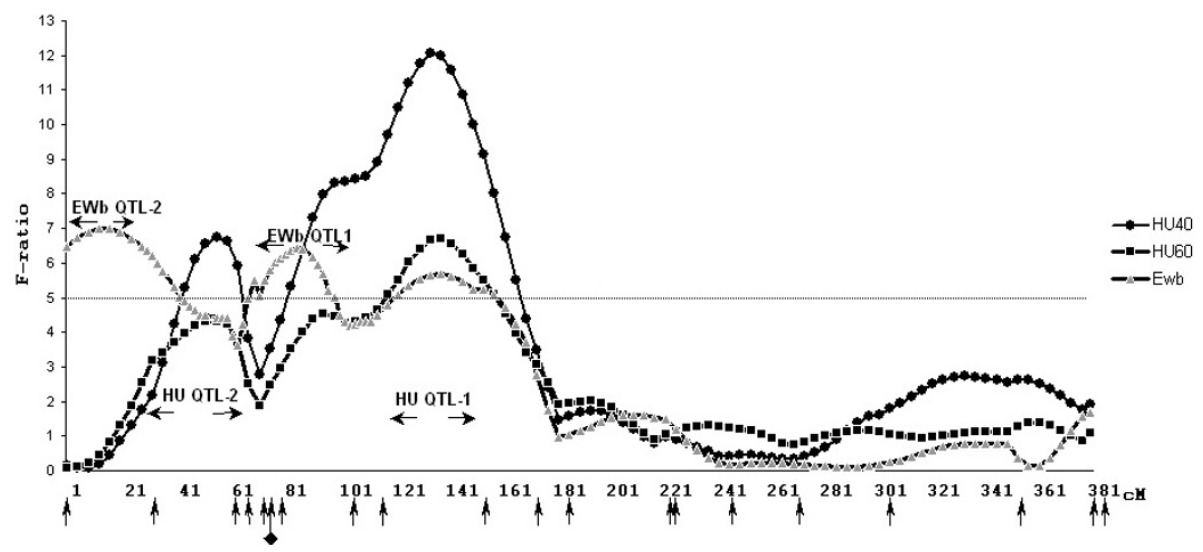

Figure 1. HU40, HU60 and EWb QTL profiles from single QTL analysis expressed as $\mathrm{F}$ ratios. The significance of the $5 \%$ chromosome-wide level is marked as a dotted line. Marker positions are indicated with an arrow in the following order: ADL0228, MCW0082, ADL0190, MCW0220, LEI0117, VIMint4, MCW0247, MCW0243, MCW206E, ADL0217, MCW0065, LEI0089, ADL0197, MCW0039, MCW0041, ADL0267, ADL0236, MCW0264, MCW0056, MCW0166. The SNP marker VIMint4 is marked with a squared arrow.

placed vimentin at $78 \mathrm{cM}$. Regarding the other polymorphisms, no concordant sequence differences between phenotypic groups (low or high HU) were identified.

\section{DISCUSSION}

Two QTL areas (HU QTL-1 and HU QTL-2) affecting egg white thinning were detected on chromosome 2 within a $100 \mathrm{cM}$ region (Fig. 1). Within the two areas, the most probable locations of the QTL affecting quality at high (HU40) or late (HU60) production periods coincide quite closely (at QTL-1 HU40 at $137 \mathrm{cM}$ versus $\mathrm{HU} 60$ at $139 \mathrm{cM}$ and at QTL-2 HU40 at $54 \mathrm{cM}$ versus HU60 at $32 \mathrm{cM}$ ) suggesting that there is a single QTL at both locations affecting each egg white traits (HU40, HU60) fairly equally. Therefore it seems that the genetic contribution for both traits are at least in part equal. The RIR allele effect at both locations for both production periods is negative, as expected from the line characteristics.

Additional support for QTL affecting egg weight in the late production period was gained: two QTL were indicated using the denser map. The new positions located on both sides of the former marker gap. The effect of the RIR allele on egg weight was also negative. 
It is difficult to interpret the exact number and positions of the egg weight QTL. The shape of the test statistic curve shows three separate QTL peaks within a $180 \mathrm{cM}$ area. The most unambiguous EWb QTL position is at the beginning of the chromosome $(12 \mathrm{cM})$. This position is separate from the other QTL positions, thus apparently not connected with the HU QTL. A second peak was detected at $81 \mathrm{cM}$, where the test statistic was slightly higher (0.7 F-units) than at the third peak at $141 \mathrm{cM}$. Whether the mid peak is a real QTL or a ghost from two flanking QTL cannot be resolved using the current QTL mapping software. The third peak (141 cM) overlaps HU QTL-1, raising the possibility of a QTL with pleiotropic effects on all traits. The positions of the QTL found for egg white quality coincided also on other chromosomes with those of the egg weight QTL in our earlier study. On chromosome 4, a genome-wide significant EWb QTL located at the same position as a chromosome-wide significant egg white quality QTL. Moreover, on chromosome 8, the best positions of QTL affecting $\mathrm{HU}$ and EWb were the same, even though EWb was not significant. Nevertheless, not all test statistic peaks for EWb and $\mathrm{HU}$ overlapped, also indicating separate effects. For instance, an EWb QTL region on chromosome Z does not show any effect on HU. Including multiple traits in the analysis could help to discriminate between pleiotropic effects of one QTL and multiple linked QTL.

It has been established that older hens have significantly larger pre-ovulatory follicles than younger ones [14]. Probably the age dependent deceleration of ovulation rate and reduced recruitment of follicles prolongs the duration of follicular growth allowing follicles to maturate over a longer time. In general, greater weight of eggs is associated with lower yolk to white ratio and increased proportion of albumen $[1,12,33]$, suggesting that albumen is the major factor affecting the egg size.

The relevance of the Haugh value as an indicator of egg white thinning through the complete production period has been criticised [7, 22, 29]. Because the Haugh value is a function of the height of the thick albumen and the weight of the egg, it will always be dependent on egg weight. Thus, especially for heavy eggs (eggs of old hens), Haugh values could be biased and might not be comparable for eggs of medium weight. Some of the coincidences of late production period egg weight and albumen quality QTL might be due to the formula used for calculating the Haugh value. However, there was no significant phenotypic correlation between these traits in our data. No inherent relationships were found between egg weight and albumen height by Silversides and Scott [28] either. 
The relevance of the dominance effect on egg white thinning remains unresolved; at the HU QTL-2 it may indicate mixed effects of two (closely) linked QTL rather than a single over-dominant effect. On the contrary, in our previous study a similar QTL area affecting HU40 was found on chromosome 8: the additive effect was not substantial, whereas the dominance effect was significant [35]. Also, Redman and Shoffner [20] and Poggenpoel [19] reported the dominance to be much more significant than the additive variation in egg white quality.

Egg white quality was measured as two traits defined by the laying period (high production vs. late). The phenotypic correlation between the traits was 0.48 in the dataset. Several estimates for the genetic correlations for Haugh values between fresh and stored eggs have been reported, ranging between 0.36 and 0.99 depending on the breed and age of the hen $[18,19]$. However, there are no published estimates for genetic correlation between HU40 and HU60. In practice, usually the $\mathrm{HU}$ values are poorer in the late period, as was also the case in the mapping population [34]. The phenotypic variance (standard deviation) of Haugh values was wider in the later laying period, but the result from QTL analysis was less significant than for the early laying period. Moreover, the proportion of other polygenic effects was smaller for HU60 QTL than for HU40 QTL; probably non-genetical, environmental effects influence the late egg white quality to a greater extent. A similar tendency was reported by Washburn [41] and Ledur et al. [16]. Therefore one could draw a conclusion that Haugh measurements in the early laying period seem to reflect the genetic component better than in the late laying period.

The confidence intervals for the QTL areas are still too large for accurate gene targeting. Likewise the marker allele haplotypes are inadequate for marker-assisted selection (MAS). Differentiating the effects of closely linked QTL from the effects of one pleiotropic QTL remains problematic in segregating populations of modest size. In order to be able to separate multiple linked QTL one should have mapping populations over several generations or a very large population in order to get enough recombinants. A linkage relationship will be broken in the following generations, while pleiotropic effects will remain unaltered.

Although the confidence interval(s) for the QTL location(s) were still large, we searched for candidate genes within the area. The strongest candidate was vimentin, an evolutionarily highly conserved structural gene located within the initial HU QTL area. Sequencing vimentin did not reveal any consistent differences in its protein coding sequence between individuals with high and low $\mathrm{HU}$ values. Subsequent analysis using the SNP within the gene as a marker 
in the QTL analysis did not suggest that vimentin could explain the effect on egg albumen thinning since the locus fell between the QTL regions of the current study (Fig. 1). Haplotype combinations of vimentin polymorphisms were not analysed from the mapping population, although this might have yielded additional information. A recent publication of the chicken genome sequence (http://www.ensembl.org/Gallus_gallus) provides new, more efficient ways to screen for possible candidate genes.

In summary, we prove that there are at least two QTL regions affecting egg white quality and/or egg weight on chicken chromosome 2. Some of the coinciding QTL effects on quality and egg weight may be caused by one QTL in some way regulating the biological changes usually seen in eggs during the late production period (i.e. increase of egg size and deterioration of egg white quality). In this mapping population, the WL allele effects on both traits were positive, indicating that at least regarding these QTL, it could be possible to break the negative correlation between egg production and egg white quality.

\section{ACKNOWLEDGEMENTS}

We are grateful to Anni Järvinen and Laura Lauttamäki for expert technical assistance.

\section{REFERENCES}

[1] Ahn D.U., Kim S.M., Shu H., Effect of egg size and strain and age of hens on the solids content of chicken eggs, Poult. Sci. 76 (1997) 914-919.

[2] Benton C.E. Jr, Walsh T.J., Brake J., Effects of presence of a blastoderm on albumen height and pH of broiler hatching eggs, Poult. Sci. 80 (2001) 955-957.

[3] Burley R.W., Vadehra D.V., The Avian Egg, Chemistry and Biology. John Wiley \& Sons, New York, 1989.

[4] Carlborg O., Kerje S., Schutz K., Jacobsson L., Jensen P., Andersson L., A global search reveals epistatic interaction between QTL for early growth in the chicken, Genome Res. 13 (2003) 413-421.

[5] de Koning D.J., Rattink A.P., Harlizius B., van Arendonk J.A., Brascamp E.W., Groenen M.A., Genome-wide scan for body composition in pigs reveals important role of imprinting, Proc. Natl. Acad. Sci. USA 97 (2000) 7947-7950.

[6] de Koning D.J., Windsor D., Hocking P.M., Burt D.W., Law A., Haley C.S., Morris A., Vincent J., Griffin H., Quantitative trait locus detection in commercial broiler lines using candidate regions, J. Anim. Sci. 81 (2003) 1158-1165.

[7] Eisen E.J., Bohren B.B., McKean H.E., The Haugh unit as a measure of egg albumen quality, Poult. Sci. 41 (1962) 1461-1468. 
[8] Gowe R.S., Fairfull R.W., Breeding and genetics of laying chickens pages, in: Hunton P. (Ed.), World Animal Science - C. Production System Approach, Poultry Production, Elsevier Science, Amsterdam, 1995, pp. 435-455.

[9] Green P., Falls K., Crooks S., Documentation for CRI-MAP, version 2.4, 1990. http://www.genome.iastate.edu/ hu/CRIMAPwkshp/crimap-doc.html

[10] Groenen M.A.M., Crooijmans R.P.M.A., Veenendaal T., van Kaam J.B., Vereijken A.L.J., van Arendonk J.A.M., van der Poel J.J., QTL mapping in chicken using a three generation full sib family structure of an extreme broiler $\times$ broiler cross, Anim. Biotechnol. (1997) 841-846.

[11] Haugh R.R., The Haugh unit or measuring egg quality, The US Egg and Poult. Magazine 43 (1937) 522-555, 572-573.

[12] Hocking P.M., Bain M., Channing C.E., Fleming R., Wilson S., Genetic variation for egg production, egg quality and bone strength in selected and traditional breeds of laying fowl, Br. Poult. Sci. 44 (2003) 365-377.

[13] Ikeobi C.O., Woolliams J.A., Morrice D.R., Law A., Windsor D., Burt D.W., Hocking P.M., Quantitative trait loci affecting fatness in the chicken, Anim. Genet. 33 (2002) 428-435.

[14] Joyner C.J., Peddie M.J., Taylor T.G., The effect of age on egg production in the domestic hen, Gen. Comp. Endocrinol. 65 (1987) 331-336.

[15] Kerje S., Carlborg O., Jacobsson L., Schutz K., Hartmann C., Jensen P., Andersson L., The twofold difference in adult size between the red junglefowl and White Leghorn chickens is largely explained by a limited number of QTLs, Anim. Genet. 34 (2003) 264-274.

[16] Ledur M.C., Liljedahl L.E., McMillan I., Asselstine L., Fairfull R.W., Genetic effects of aging on egg quality traits in the first laying cycle of White Leghorn strains and strain crosses, Poult. Sci. 81 (2002) 1439-1447.

[17] Li-Chan E., Shuryo N., Biochemical basis for the properties of egg white, Crit. Rev. Poult. Biol. 2 (1989) 21-58.

[18] May K.N., Schmidt F.J., Stadelman W.J., Strain variation in albumen quality decline of hen's eggs, Poult. Sci. 36 (1957) 1376-1379.

[19] Poggenpoel D.G., Correlated response in the shell and albumen quality with selection for increased egg production, Poult. Sci. 65 (1986) 1633-1641.

[20] Redman C.E., Shoffner R.N., Estimates of egg quality parameters utilizing a polyallelo crossing system, Poult. Sci. (1961) 1663-1675.

[21] Robinson D.S., The chemical basis of albumen quality, in: Wells R.G., Belyavin C.G. (Eds.), Egg quality - Current problems and recent advances, Butterworths, London, 1987, pp. 171-191.

[22] Rossi M., Hidalgo A., Pompei C., Reaction between albumen and 3,3',5,5'tetramethylbenzidine as a method to evaluate egg freshness, J. Agric. Food Chem. 49 (2001) 3522-3526.

[23] Sarria A.J., Lieber J.G., Nordeen S.K., Evans R.M., The presence or absence of a vimentin-type intermediate filament network affects the shape of the nucleus in human SW-13 cells, J. Cell. Sci. 107 (1994) 1593-1607.

[24] Sasaki O., Odawara S., Takahashi H., Nirasawa K., Oyamada Y., Yamamoto R., Ishii K., Nagamine Y., Takeda H., Kobayashi E., Furukawa T., Genetic mapping 
of quantitative trait loci affecting body weight, egg character and egg production in F2 intercross chickens, Anim. Genet. 35 (2004) 188-194.

[25] Schmid M., Nanda I., Guttenbach M., Steinlein C., Hoehn M., Schartl M., Haaf T., Weigend S., Fries R., Buerstedde J.M., Wimmers K., Burt D.W., Smith J., A'Hara S., Law A., Griffin D.K., Bumstead N., Kaufman J., Thomson P.A., Burke T., Groenen M.A., Crooijmans R.P., Vignal A., Fillon V., Morisson M., Pitel F., Tixier-Boichard M., Ladjali-Mohammedi K., Hillel J., Mäki-Tanila A., Cheng H.H., Delany M.E., Burnside J., Mizuno S., First report on chicken genes and chromosomes 2000, Cytogenet. Cell Genet. 90 (2000) 169-218.

[26] Seaton G., Haley C.S., Knott S.A., Kearsey M., Visscher P.M., QTL Express: mapping quantitative trait loci in simple and complex pedigrees, Bioinformatics 18 (2002) 339-340. http://qtl.cap.ed.ac.uk

[27] Sewalem A., Morrice D.M., Law A., Windsor D., Haley C.S., Ikeobi C.O., Burt D.W., Hocking P.M., Mapping of quantitative trait loci for body weight at three, six, and nine weeks of age in a broiler layer cross, Poult. Sci. 81 (2002) 1775-1781.

[28] Silversides F.G., Scott T.A., Effect of storage and layer age on quality of eggs from two lines of hens, Poult. Sci. 80 (2001) 1240-1245.

[29] Silversides F.G., Twizeyimana F., Villeneuve P., Research note: a study relating to the validity of the Haugh unit correlation for egg weight in fresh eggs, Poult. Sci. 72 (1993) 760-764.

[30] Skalli O., Goldman R.D., Recent insights into the assembly, dynamics, and function of intermediate filament networks, Cell Motil. Cytoskel. 19 (1991) 67-79.

[31] Summers J.D., Robinson F.E., Comparative feeding programs for poultry reproduction, in: Hunton P. (Ed.), World Animal Science C9. Production-system approach, Elsevier Amsterdam, 1995, pp. 319-434.

[32] Tatsuda K., Fujinaka K., Genetic mapping of the QTL affecting body weight in chickens using a F2 family, Br. Poult. Sci. 42 (2001) 333-337.

[33] Tharrington J.B., Curtis P.A., Jones F.T., Anderson K.E., Comparison of physical quality and composition of eggs from historic strains of single comb white leghorn chickens, Poult. Sci. 78 (1999) 591-594.

[34] Tuiskula-Haavisto M., Quantitative trait loci for egg quality and production in laying hens (doctoral dissertation), Agrifood Research Reports 58, MTT Agrifood Research Finland, 2004.

[35] Tuiskula-Haavisto M., Honkatukia M., Vilkki J., de Koning D.J., Schulman N.F., Mäki-Tanila A., Mapping of quantitative trait loci affecting quality and production traits in egg layers, Poult. Sci. 81 (2002) 919-927.

[36] Vallejo R.L., Bacon L.D., Liu H.C., Witter R.L., Groenen M.A., Hillel J., Cheng H.H., Genetic mapping of quantitative trait loci affecting susceptibility to Marek's disease virus induced tumors in F2 intercross chickens, Genetics 148 (1998) 349-360.

[37] van Kaam J.B., Groenen M.A., Bovenhuis H., Veenendaal A., Vereijken A.L., van Arendonk J.A., Whole genome scan in chickens for quantitative trait loci affecting growth and feed efficiency, Poult. Sci. 78 (1999) 15-23. 
[38] van Kaam J.B., Groenen M.A., Bovenhuis H., Veenendaal A., Vereijken A.L., van Arendonk J.A.M., Whole genome scan in chickens for quantitative trait loci affecting carcass traits, Poult. Sci. 78 (1999) 1091-1099.

[39] Visscher P.M., Thompson R., Haley C.S., Confidence intervals in QTL mapping by bootstrapping, Genetics 143 (1996) 1013-1020.

[40] Wardecka B., Olszewski R., Jaszczak K., Zieba G., Pierzchala M., Wicinska K., Relationship between microsatellite marker alleles on chromosomes 1-5 originating from the Rhode Island Red and Green-legged Partrigenous breeds and egg production and quality traits in $\mathrm{F}_{2}$ mapping population, J. Appl. Genet. 43 (2002) 319-329.

[41] Washburn K.W., Genetic variation in egg composition, in: Crawford R.D. (Ed.), Poultry Breeding and Genetics, Elsevier Amsterdam, 1990, pp. 781-798.

[42] Yonash N., Bacon L.D., Witter R.L., Cheng H.H., High resolution mapping and identification of new quantitative trait loci (QTL) affecting susceptibility to Marek's disease, Anim. Genet. 30 (1999) 126-135.

[43] Yonash N., Cheng H.H., Hillel J., Heller D.E., Cahaner A., DNA microsatellites linked to quantitative trait loci affecting antibody response and survival rate in meat-type chickens, Poult. Sci. 80 (2001) 22-28.

[44] Yunis R., Heller E.D., Hillel J., Cahaner A., Microsatellite markers associated with quantitative trait loci controlling antibody response to Escherichia coli and Salmonella enteritidis in young broilers, Anim. Genet. 33 (2002) 407-414.

[45] Zehner Z.E., Li Y., Roe B.A., Paterson B.M., Sax C.M., The chicken vimentin gene. Nucleotide sequence, regulatory elements, and comparison to the hamster gene, J. Biol. Chem. 262 (1987) 8112-8120.

[46] Zhu J.J., Lillehoj H.S., Allen P.C., van Tassell C.P., Sonstegard T.S., Cheng H.H., Pollock D., Sadjadi M., Min W., Emara M.G., Mapping quantitative trait loci associated with resistance to coccidiosis and growth, Poult. Sci. 82 (2003) 9-16. 